XV- 1205-06, XV-F-74-06

\title{
Special cases of the calculation of residual welding distortions
}

\author{
J. Farkas \\ K. Jármai \\ University of Miskolc, Hungary
}

\begin{abstract}
In the first part the calculation of residual deflection of a welded beam with variable crosssection due to shrinkage of an eccentric longitudinal weld is presented. The Okerblom's method is used and the bending moment of the diagram of curvatures as a virtual load gives the deflection. The second part treats the calculation of the angular distortion of the flange of a welded I-beam due to transverse shrinkage of the fillet welds connecting the flange to the web. The Masubuchi's diagram predicts the measure of this angular distortion. To eliminate this distortion prestraining can be used. The Kumoze's diagram helps the design of a prestraining jig. The calculation is illustrated by numerical examples.
\end{abstract}

KEYWORDS: Residual welding distortions; welded beam; beam deflection; angular distortion; prestraining. 


\section{INTRODUCTION}

The main requirements of modern welded structures are the safety, fitness for production and economy. In the optimum design the safety and production requirements are fulfilled by design and fabrication constraints and the economy is achieved by minimization of a cost function. Fabrication aspects are very important for welded structures, since the distortions caused by shrinkage of welds should be limited. For fabrication constraints a relatively simple calculation method is developed, which enables to predict the residual welding stresses and distortions

The books of Okerblom [1], Vinokurov [2], Masubuchi [3] and Kuzminov [4] give suitable calculation methods, which have been adapted and applied by the authors $[5,6,7,8]$. In the present paper two special cases of distortion calculation are detailed, which have not been treated in our previous studies.

\section{RESIDUAL DEFLECTIONS DUE TO SHRINKAGE OF ECCENTRIC LONGITUDINAL WELDS IN THE CASE OF SIMPLY SUPPORTED BEAMS WITH VARIABLE CROSS-SECTION}

The basic Okerblom's formulae are as follows:

the residual strain at the center of gravity and the curvature for steels can be calculated as $[5,6]$

$$
\begin{gathered}
\varepsilon_{G}=0.844 \times 10^{-3} \frac{Q_{T}}{A} \\
C=0.844 \times 10^{-3} \frac{Q_{T} y_{T}}{I_{x}}
\end{gathered}
$$

where

$$
Q_{T}=\eta_{0} \frac{U I_{w}}{v_{w}}=\eta_{0} \frac{3600 U[V] \rho}{\alpha_{N}} A_{w}
$$

is the thermal impulse due to welding, $U[\mathrm{~V}]$ arc voltage, $I_{w}$ arc current, $v_{w}$ speed of welding, $\eta_{0}$ thermal efficiency, $A$ cross-sectional area, $I_{x}$ moment of inertia of the beam cross-section, $A_{w}$ cross-sectional area of the weld, $\rho=7.85 \times 10^{-6} \mathrm{~kg} / \mathrm{m}^{3}$ is the density of steel, $\alpha_{N}=8.8 \times 10^{-3} \mathrm{~kg} / \mathrm{Ah}$ (Amper-hour) is the coefficient of penetration..

The second expression of Eq.(3) can be derived in following way. The mass of penetrated metal during a weld pass lasting $t[\mathrm{~s}]$ time can be calculated as

$$
m[k g]=\frac{\alpha_{N} I_{w}[A] t[s]}{3600}
$$

This mass can also be expressed as

$$
m=A_{w} L \rho
$$


$L$ is the weld length. Combining Eqs. (4) and (5) the welding speed can be calculated as

$$
v_{w}[\mathrm{~mm} / \mathrm{s}]=\frac{L[\mathrm{~mm}]}{t[\mathrm{~s}]}=\frac{\alpha_{N} I_{w}}{3600 \rho A_{w}}
$$

Substituting Eq.(6) into Eq.(3) one obtains the second expression.

With values of $U=27 \mathrm{~V}, \eta_{0}=0.7$ for butt welds

$$
Q_{T}(\mathrm{~J} / \mathrm{mm})=60.7 A_{w}\left(\mathrm{~mm}^{2}\right),
$$

for SMAW (shielded metal arc welding) fillet welds

$$
Q_{T}=78.8 A_{w}
$$

and for GMAW (gas metal arc welding) of SAW (submerged arc welding) fillet welds

$$
Q_{T}=59.5 A_{w}
$$

The maximum deflection due to shrinkage of a single eccentric longitudinal weld in the case of a simply supported beam of constant cross-section can be calculated using the correlation between the distributed load $\mathrm{p}$, bending moment $\mathrm{M}$ and deflection $\mathrm{w}$

$$
\frac{d^{2} M(z)}{d z^{2}}=p(z)
$$

and

$$
\frac{d^{2} w(z)}{d z^{2}}=\frac{M(z)}{E I_{x}}=C
$$

i.e. the deflection can be obtained by calculating the bending moment considering the bending moment diagram as a virtual loading (Fig.1)

$$
w_{\max }=\frac{M L}{2 E I_{x}} \cdot \frac{L}{4}=\frac{M L^{2}}{8 E I_{x}}=\frac{C L^{2}}{8}
$$

In the case of a beam of variable cross-section (Fig.2), instead of $M$-diagram the variable $C$ diagram should be considered as a virtual loading and its bending moment gives the deflection. In the case of the beam shown in Figure 2 approximately an average height and the corresponding $C_{1}$ can be considered instead of complicated variable $C$ in the beam parts with linearly varied beam height. Thus

$$
w_{\max }=\left(C_{1} L_{1}+C_{0} \frac{L_{0}}{2}\right)\left(L_{1}+\frac{L_{0}}{2}\right)-C_{1} L_{1} \frac{L_{1}}{2}-C_{0} \frac{L_{0}}{2} \cdot \frac{L_{0}}{4}
$$

where 
$C_{0}=0.844 \times 10^{-3} \frac{Q_{T 0} y_{T 0}}{I_{x 0}} \cdot C_{1}=0.844 \times 10^{-3} \frac{Q_{T 1} y_{T 1}}{I_{x 1}}$

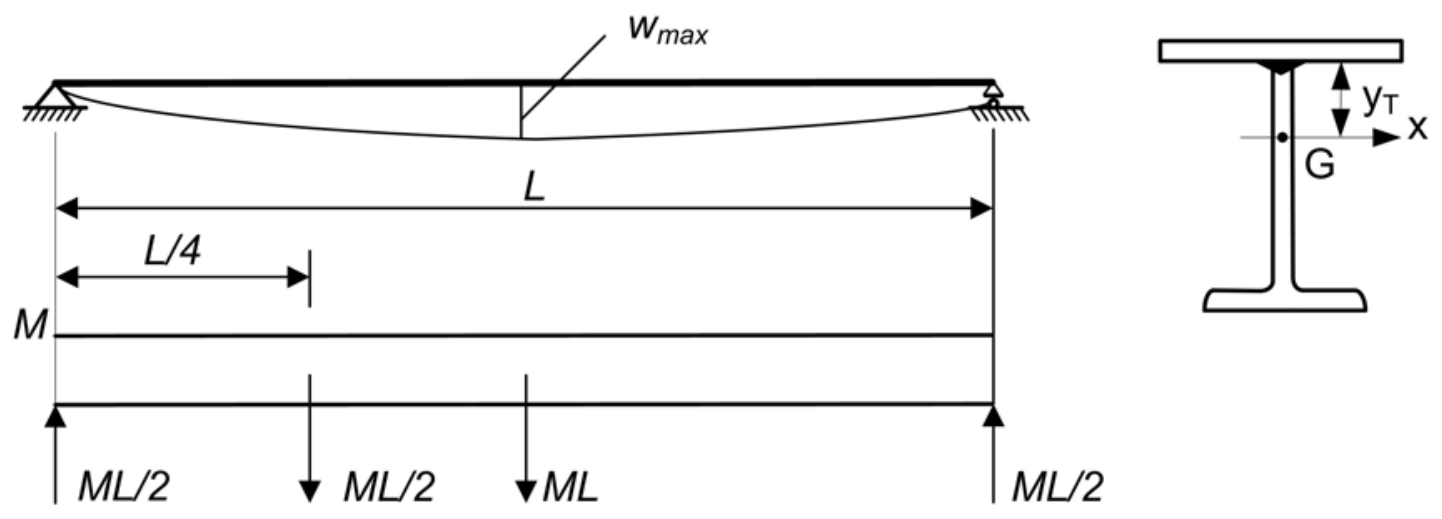

Figure 1-- Calculation of the maximum deflection for a welded beam of constant crosssection

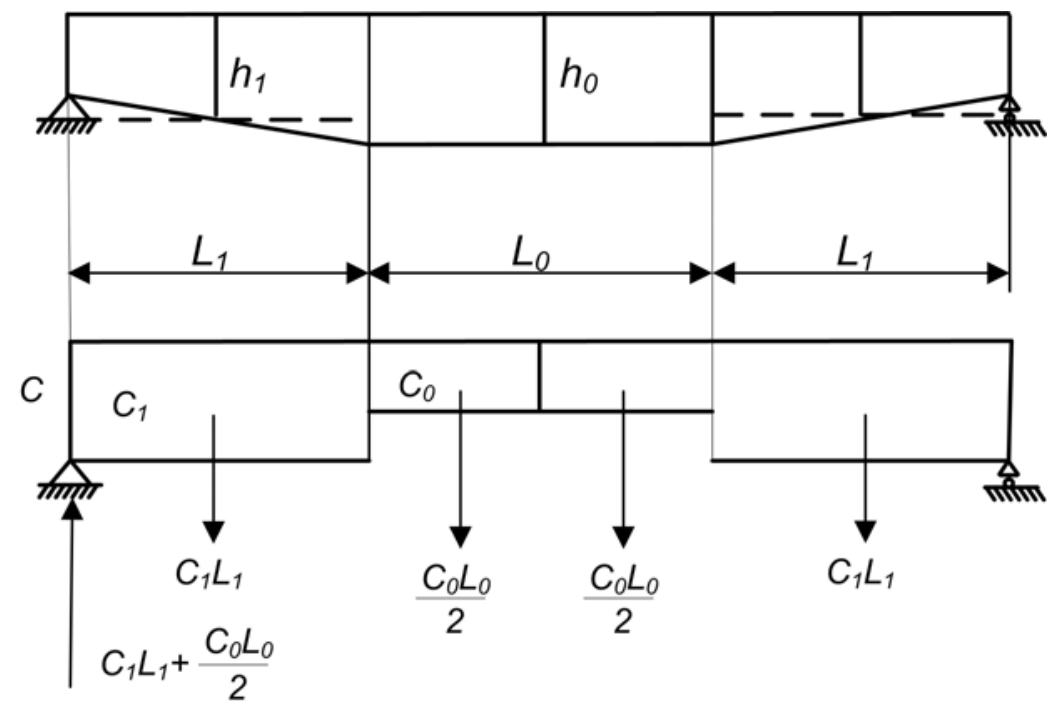

Figure 2 -- Calculation of deflections for a beam of variable cross-section

It should be noted that, for the more correct calculation, the beam parts of variable crosssection can be divided in more parts of constant cross-section.

\section{Numerical example}

Calculate the maximum residual deflection of a beam of asymmetric cross-section with parts of linearly varied web height (Fig.3) due to the shrinkage of two eccentric longitudinal welds connecting the two angles to an rolled I-section. The angles strengthen the I-beam against lateral torsional buckling e.g. in the case of a crane runway.

The weld eccentricities and moments of inertia for the two beam parts of different web heights are as follows: 

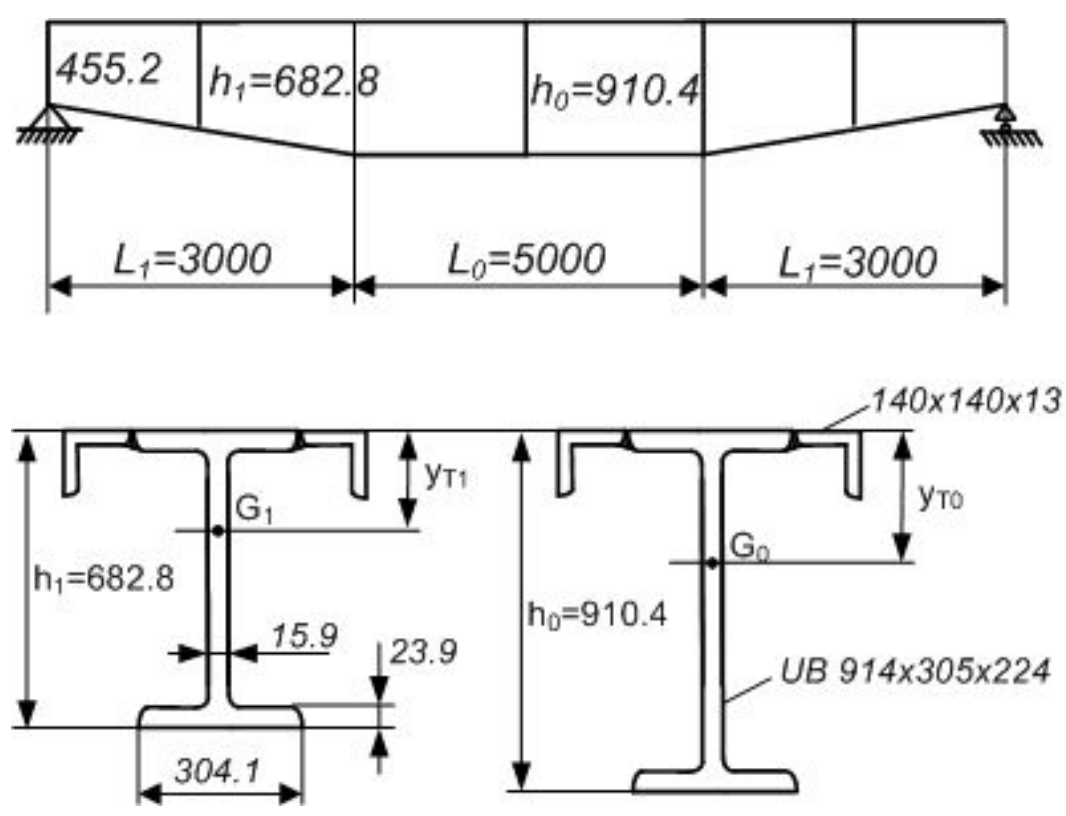

Figure 3 -- Numerical example of a welded beam of variable cross-section

For the original height at the mid-span $h_{0}=910.4 \mathrm{~mm} \quad y_{T 0}=373 \mathrm{~mm}, \quad I_{x 0}=47.4858 \times 10^{8}$ $\mathrm{mm}^{4}$, for the decreased height $h_{1}=682.8 \mathrm{~mm} y_{T 1}=274.6 \mathrm{~mm}$ and $I_{x 1}=22.9347 \times 10^{8} \mathrm{~mm}^{4}$.

The thermal impulse due to welding of two single bevel (1/2V) longitudinal butt welds of size $a_{w}=13 \mathrm{~mm}\left(A_{w}=170 \mathrm{~mm}^{2}\right)$ is

$2 Q_{T}=2 \times 60.7 \times 170=20638 \mathrm{~J} / \mathrm{mm}$.

With Eq.(14) $C_{0}=1.3682 \times 10^{-6} \mathrm{~mm}^{-1}, C_{1}=2.0855 \times 10^{-6} \mathrm{~mm}^{-1}$, and the maximum deflection for $L_{0}=5000$ and $L_{1}=3000 \mathrm{~mm}$ with Eq. (13) is $w_{\max }=39.6 \mathrm{~mm}$.

For a beam of constant $I_{x 0}$ with Eq. (12) $w^{\prime}{ }_{\max }=20.7 \mathrm{~mm}$.

\section{ANGULAR DEFORMATION DUE TO TRANSVERSE SHRINKAGE OF FILLET WELDS}

The angular deformation due to transverse shrinkage of fillet welds can cause a distortion of flanges of welded I-beams (Fig.4). This can result in difficulties in fabrication of these beams. e.g. in assembly of vertical stiffeners or in connection of transverse beams.

Masubuchi [3] has given a diagram for angular deformation in function of plate thickness for different values of the mass of consumed electrode per unit weld length $w$ (Fig.5).

$$
w(\mathrm{~g} / \mathrm{cm})=a_{w}^{2} 10^{-2} \rho / \eta_{0}=a_{w}^{2} 10^{-2} x 7.85 / 0.677=0.1160 a_{w}^{2}
$$




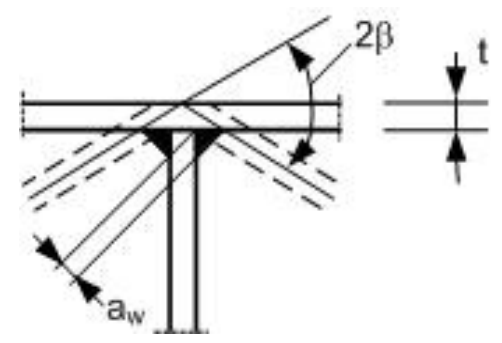

Figure 4 -- Residual angular deformation due to shrinkage of fillet welds

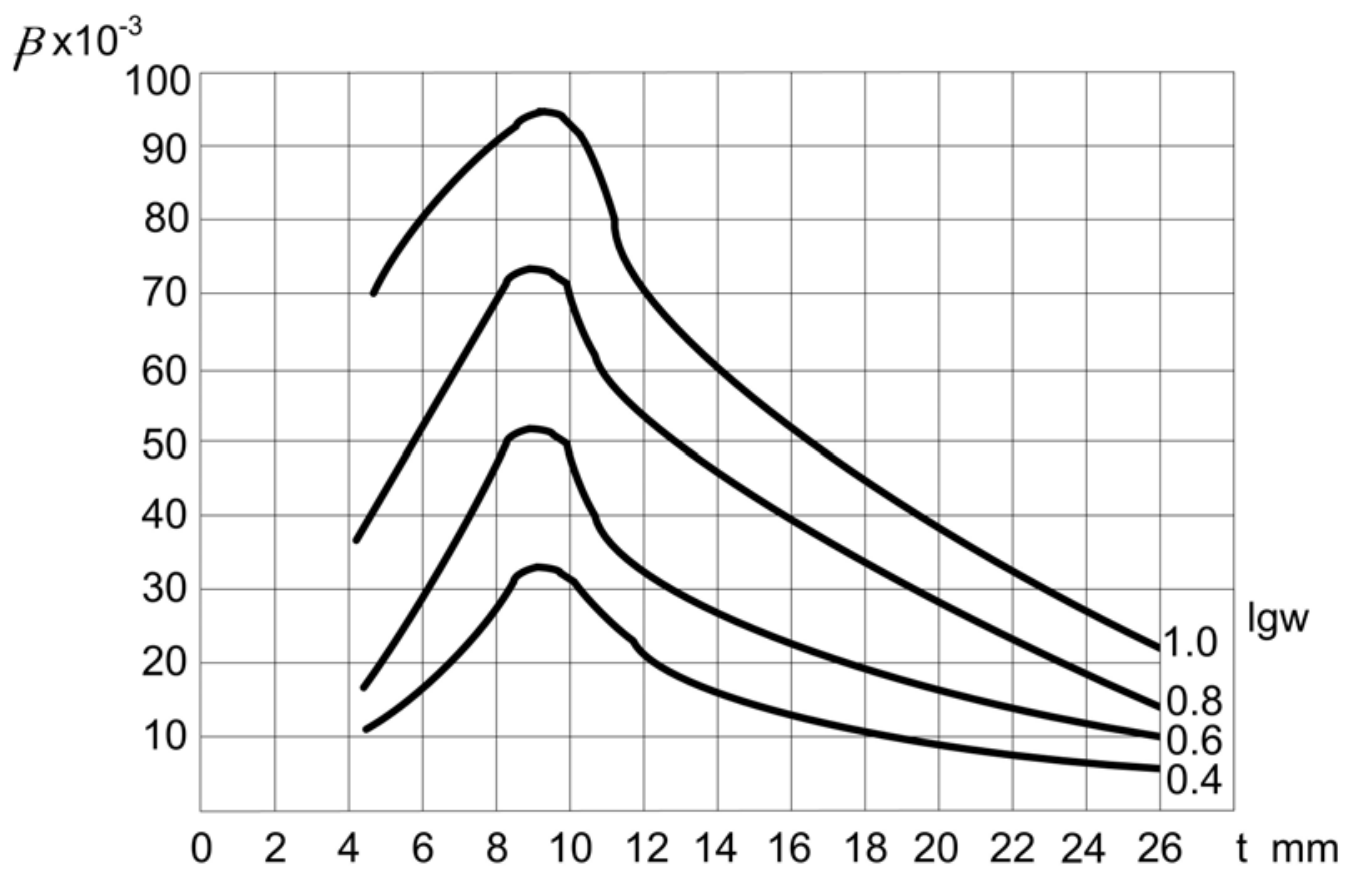

Figure 5 -- Angular deformation in the function of plate thickness and fillet weld size

The values of lgw are given in Table 1.

The diagram in Figure 5 has been obtained using covered electrodes $5 \mathrm{~mm}$ in diameter for steels. The maximum angular changes were obtained for plate thickness approximately $9 \mathrm{~mm}$. When the plate was thinner than $9 \mathrm{~mm}$, the angular deformation was reduced with plate thickness. This is because the plate was heated more in the thickness direction, thus reducing the bending moment. On the other hand, when the plate thickness is larger than $9 \mathrm{~mm}$, the angular deformation decreases because of larger plate rigidity.

Table 1 -- Values of lgw for different fillet weld sizes

\begin{tabular}{|c|c|c|}
\hline$a_{w}(\mathrm{~mm})$ & $w(\mathrm{~g} / \mathrm{cm})$ & $\lg w$ \\
\hline 5 & 2.9 & 0.46 \\
\hline 6 & 4.2 & 0.62 \\
\hline 7 & 5.7 & 0.75 \\
\hline 8 & 7.4 & 0.87 \\
\hline 9 & 9.4 & 0.97 \\
\hline
\end{tabular}


The residual angular deformation can be decreased or eliminated by prestraining. Figure 6 shows a prestraining jig. The required diameter $D$ of a prestraining round bar can be calculated comparing the stress in the flange plate initiated by prestressing with the stress required to eliminate the distortion.

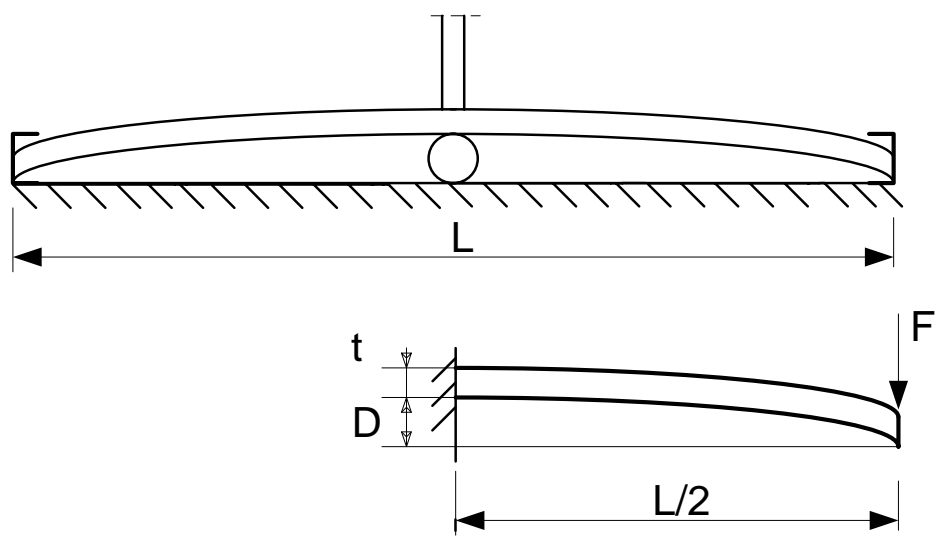

Figure 6 -- Prestraining a beam flange to eliminate the angular deformation

The elastic deflection caused by a force $F$ is

$$
D=\frac{F(L / 2)^{3}}{3 E I_{x}}=\frac{F L^{3}}{2 E t^{3}} ; \quad I_{x}=\frac{t^{3}}{12}
$$

from which

$$
F=\frac{2 E t^{3} D}{L^{3}}
$$

The stress from bending moment $F L / 2$ is

$$
\sigma=\frac{F L / 2}{t^{2} / 6}=\frac{3 F L}{t^{2}}=\frac{6 E t D}{L^{2}}
$$

From Eq.(18) the required diameter of the prestraining round bar is

$$
D_{r}=\frac{\sigma_{r} L^{2}}{6 E t}
$$

Based on experiments Kumose et al. [3,9] have given a diagram for required prestraining stress $\sigma_{r}$ in function of plate thickness and fillet weld size (Fig.7).

Numerical example

Flange plate thickness $t=10$, width $L=700 \mathrm{~mm}$, fillet weld size $a_{w}=5 \mathrm{~mm}$, elastic modulus for steels is $E=2.1 \times 10^{5} \mathrm{MPa}$.

From Table $1 \lg w=0.46$, using diagram of Figure $5 \beta=0.035\left(2^{0}\right)$. 
According to the diagram of Figure $7 \sigma_{r}=90 \mathrm{MPa}$ and Eq.(19) gives $D_{r}=3.5 \mathrm{~mm}$.

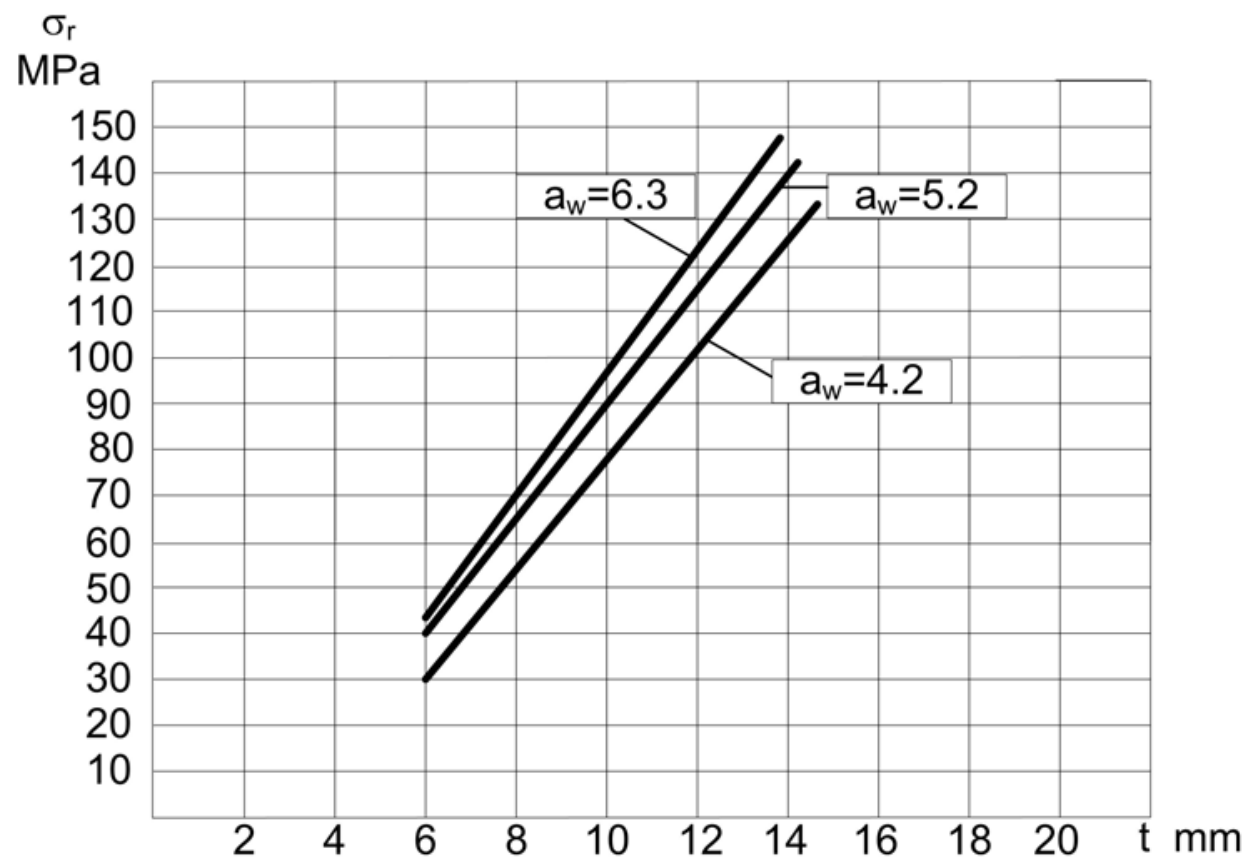

Figure 7 -- Required prestress to eliminate the angular distortion

\section{CONCLUSIONS}

Two special cases of the prediction of residual welding distortions are presented. The Okerblom's calculation method of beam deflection due to shrinkage of longitudinal eccentric welds is extended to the case of beams of variable cross-section. The deflections of a simply supported welded beam can be calculated using the diagram of curvatures as a virtual load.

The angular deformation of a welded I-beam flange due to transverse shrinkage of fillet welds can be predicted using the Masubuchi's diagram in function of plate thickness and fillet weld size. The measure of prestraining to eliminate the angular distortion can be predicted using the Kumose's experimental data.

Both cases are illustrated by numerical examples.

\section{ACKNOWLEDGEMENTS}

The research work was supported by the Hungarian Scientific Research Foundation grants OTKA T38058, T37941.

\section{REFERENCES}

[1] Okerblom N.O., Demyantsevich V.P., Baikova I.P.: Design of fabrication technology of welded structures (in Russian). Leningrad, Sudpromgiz, 1963.

[2] Vinokurov V.A.: Welding stresses and distortion. (Translated from Russian). Boston Spa, Wetherby, England, The British Library, 1977. 
[3] Masubuchi K.: Analysis of welded structures. Pergamon Press, Oxford, New York etc. 1980.

[4] Kuzminov S.A.: Welding deformations of ship structures (in Russian). Leningrad, Sudostroenie, 1974.

[5] Farkas J. ,Jármai K.: Analysis and optimum design of metal structures. Balkema, Rotterdam-Brookfield, 1997.

[6] Farkas J., Jármai K. Analysis of some methods for reducing residual beam curvatures due to weld shrinkage, Welding in the World 1998, 41 (4) 385-398.

[7] Farkas,J. Thickness design of axially compressed unstiffened cylindrical shells with circumferential welds, Welding in the World 2002, 46 (11/12) 26-29.

[8] Farkas,J., Jármai,K.: Economic design of metal structures. Rotterdam, Millpress 2003.

[9] Kumose T., Yoshida T., Abbe T., Onoue H.: Prediction of angular distortion caused by one-pass fillet welding, Welding Journal 1954, 33 (10) 945-956. 